\title{
Перспективы использования метода ТСX для идентификации и оценки качества растительного сырья плюща обыкновенного
}

\author{
Брежнева Т.А., Солодухина А.А., Попова М.В., \\ Самсонова Н. Д., Сливкин А.И. \\ ФГБОУ ВО «Воронежский государственньй университет», Воронеж
}

Поступила в редакцию 16.02.2019 г.

DOI: https://doi.org/10.17308/sorpchrom.2019.19/782

Перспективными для использования в медицине являются различные виды плюща, листья которого содержат до $10 \%$ тритерпеновых сапонинов, обладающих широким спектром биологической активности. В настоящей работе проведен выбор оптимальных условий анализа сапонинсодержащих извлечений из листьев плюща обыкновенного методом ТСХ. В подобранных условиях получены хроматографические профили извлечений из листьев плюща, показана возможность их использования в качестве «отпечатков пальцев» для идентификации растительного сырья плюща. Установлена вариабельность хроматографических профилей извлечений из листьев плюща в зависимости от места произрастания растения. Полученные данные могут быть рекомендованы для использования при разработке нормативной документации на лекарственное растительное сырье плюща.

Ключевые слова: листья плюща обыкновенного, идентификация, сапонины, тонкослойная хроматография.

\section{Prospects for using the TLC method for identifying and assessing the quality of plant raw ivy}

\author{
Brezhneva T.A., Soloduhina A.A., Popova M.V., \\ Samsonova N.D., Slivkin A.I. \\ Voronezh State University, Voronezh
}

\begin{abstract}
Various ivy types are perspective for medicinal use, they contain up to $10 \%$ of triterpenic saponins in leaves and have a wide spectrum of biological activity. In this regard, the studies of the standardization of ivy plant raw materials, variability of its chemical composition, climatic features, and soil composition of the plant habitat are relevant. The aim of this study was determination of TLC method prospects for identifying and assessing the quality of ivy common raw materials, as well as evaluating the variability of chromatographic profiles depending on the plant habitat. As object of the study were used dried, chopped ivy common leaves collected in the summer period from fruitless plant shoots growing in different geographical areas: Russia (Caucasus, Crimea), Iraq, Italy. Optimal TLC conditions testing was carried out using the sum of saponins of ivy leaves extract - «the Hederix+» phytocomplex, produced by «Vitaukt-prom» LLC (Russia), as a standard.

The optimal conditions (including eluent, detection reagent, plate type, method of chromatography, sample volume) for chromatographing the amount of ivy saponins in a thin layer of sorbent were studied and selected. The optimal conditions for the process of chromatography are the following: highly efficient Sorbfill PTSH-P-V plates, sample volume $10 \mu \mathrm{l}$, eluent chloroform-methanol-water 100: 25: 3, detection reagent $0.2 \%$ para-oxybenzaldehyde alcohol solution in $1 \mathrm{M}$ sulfuric acid.
\end{abstract}


Chromatographic profiles of ivy leaves extracts were obtained in the aforesaid conditions. The obtained chromatograms are quite informative and can be used as «fingerprints» for ivy raw materials identification, since they contain from 9 (Italy, Crimea) to 12 (Iraq) saponin zones. More than 10 zones of related compounds are also detected on the chromatograms viewed in visible and UV light. The «fingerprints» differences indicate the variability of the chromatographic profiles of methanol ivy leaves extracts grown in different geographical areas. The optimal conditions for the TLC analysis of saponin-containing ivy common leaves extracts were determined. Chromatographic profiles of extracts were obtained, the possibility of using them as «fingerprints» to identify ivy plant raw materials was shown. The variability of chromatographic profiles of ivy leaves extracts and its dependence on the plant habitat were identified. The obtained data can be recommended for use in the regulatory documentation development.

Keywords: ivy's leaves, identification, saponins, thin layer chromatography.

\section{Введение}

На фоне растущего в мире интереса к фитотерапии, внимание исследователей привлекают растения, содержащие тритерпеновые сапонины, обладающие широким спектром биологической активности. К перспективным источникам тритерпеновых сапонинов можно отнести различные виды плюща в силу достаточно широкой его распространенности. Растение произрастает в Западной, Центральной и Южной Европе, Восточной Азии, в Гималаях, на Кавказе, в Иране, Ливане, Северной Африке, на Канарских островах, на юге России (Предкавказье, Черноморское побережье Кавказа, Крым) [1].

В качестве лекарственного сырья плюща используют высушенные листья (Folium Hederae helicis), содержащие до 10\% сапонинов. Растение является официнальным в некоторых европейских странах, но в России - неофицинально. В то же время зарегистрированы и разрешены к применению в РФ ряд лекарственных препаратов плюща: Геделикс, Проспан, Бронхипрет (Германия), Гербион (Словения), Пектолван плющ (Украина), содержащие экстракт листьев плюща и применяющиеся для лечения острых респираторных заболеваний, острых и хронических бронхитов как секретолитик, стимулятор моторной функции дыхательных путей [2].

В народной медицине настой из листьев плюща используют в качестве мочегонного, противовоспалительного и антисептического средства, при желудочнокишечных заболеваниях, хроническом насморке, туберкулезе легких, рахите, аменорее, почечнокаменной болезни, болезнях печени и селезенки, мочекаменной болезни, желтухе, ревматизме, подагре.

Можно предположить, что в ближайшем будущем будет поставлен вопрос о разрешении к применению в РФ в качестве официнального ЛРС растения плющ и, в частности, наиболее широко распространенного в мире его вида Плющ вьющийся (обыкновенный) (Hedera helix L.). В этом случае актуальность приобретают исследования по стандартизации растительного сырья плюща. Проведение подобных исследований невозможно без учета проблемы вариабельности химического состава исходного растительного сырья, связанной с видовой принадлежностью растения, климатическими особенностями, почвенным составом, экологическими факторами (с учетом широкой географии произрастания).

Целью настоящей работы являлось изучение перспектив использования метода ТСХ для идентификации и оценки качества растительного сырья плюща, а так же оценка вариабельности полученных хроматографических профилей в зависимости от места произрастания растения.

\section{Эксперимент}

Согласно требованиям ОФС.1.2.1.2.0003.15 «Тонкослойная хроматография» ГФ XIV, основными факторами, которые могут оказать влияние на ход определения 
и основные параметры, подлежащие нормированию при проведении анализов методом ТСХ, являются: тип и размер пластины; состав, полярность, разделительная способность, селективность элюента; способ нанесения и объем пробы; способ хроматографирования; детектирующие реагенты; визуализация и идентификация зон адсорбции на хроматограммах в видимом и ультрафиолетовом свете [3].

В первой части исследования проводили выбор оптимальных параметров хроматографирования сапонинсодержащих извлечений из листьев плюща обыкновенного с учетом влияния вышеприведенных факторов.

Отработку условий хроматографирования осуществляли, используя в качестве стандарта сумму сапонинов фитокомплекса «Хедерикс+» производства ООО «Витаукт-пром», Россия (свидетельство о государственной регистрации № RU.77.99.11.003.Е.046250.11.11 от 04.11.2011), содержащего экстракт листьев плюща обыкновенного, состав сапонинов которого (11 индивидуальных сапонинов) известен [4].

Сумму сапонинов из состава комплекса выделяли по приведенной в литературе методике [4]. К $1 \mathrm{~cm}^{3}$ фитокомплекса приливали $5 \mathrm{~cm}^{3}$ гексана. Смесь перемешивали и оставляли для расслоения жидкостей. Верхний (гексановый) слой отделяли. К полученному остатку добавляли $1 \mathrm{~cm}^{3}$ н-бутанола, предварительно насыщенного водой. Смесь перемешивали и оставляли для расслоения жидкостей. Верхний (водно-спиртовый) слой отделяли и далее использовали для отработки оптимальных условий хроматографирования и идентификации сапонинов листьев плюща методом TCX.

Для нанесения проб и получения хроматограмм применяли микрошприц МШ-10, пластины Sorbfill (Россия) нескольких типов и размеров, различные способы хроматографирования, элюенты и детектирующие реагенты, рекомендуемые литературными источниками [4-14].

Объектом второй части исследования являлись высушенные измельченные (фракция 0.2-0.5мм) листья плюща обыкновенного, заготовленные в летний период с бесплодных побегов растений, произраставших в различных географических зонах: Россия (Кавказ, Крым), Ирак, Италия.

Для получения хроматографических профилей использовали извлечения (1:10) из листьев плюща, полученные настаиванием измельченного сырья в течение 2 часов при периодическом перемешивании с различными экстрагентами: метанолом $80 \%$, этанолом 20, 40, 70 и 90\%, бутанолом и хлороформом. Стремясь к нативности получаемых извлечений, сырье предварительно не обезжиривали, извлечения получали без нагревания. По завершении настаивания извлечения отфильтровывали через бумажный фильтр, отбрасывая первые порции фильтрата, наносили на пластины и хроматографировали в отработанных ранее условиях. Для идентификации зон сапонинов на пластины наносили так же сумму сапонинов фитокомплекса «Хедерикс+. Детектирование зон БАВ: первичное, визуальное - в УФ-свете при $\lambda=365 \mathrm{Hм}$; вторичное - проявлением $0.2 \%$ раствором пара-оксибензальдегида в 1 М серной кислоте с последующим нагреванием при $100^{\circ} \mathrm{C}$. Критерием выбора экстрагента служила максимальная информативность хроматографического профиля соответствующего извлечения, оцениваемая по представительству наибольшего количества зон сапонинов, а также по присутствию максимального количества сопутствующих БАВ, дающих четко выраженные зоны на хроматограммах. В качестве наилучшего экстрагента был выбран 80\%-ный метанол, часто используемый для получения первичных сапонинсодержащих извлечений из растительного сырья [4-14]. 


\section{Обсуждение результатов}

При выборе элюирующей системы, обеспечивающей оптимальные условия хроматографирования сапонинов, рассчитывали полярность элюентов, оценивали эффективность, селективность и разделительную способность систем $[15,16]$. Для испытания выбирали элюенты, наиболее часто рекомендуемые для разделения тритерпеновых сапонинов литературными источниками [4,7]. Результаты исследования представлены в таблице 1.

Таблица 1. Основные параметры процесса хроматографического разделения сапонинов листьев плюща в различных элюентах.

\begin{tabular}{|c|c|c|c|c|c|}
\hline № зоны & $\mathrm{R}_{\mathrm{f}}$ & $\begin{array}{c}\text { Разрешаю- } \\
\text { щая способ- } \\
\text { ность R }\end{array}$ & $\begin{array}{c}\text { Селектив- } \\
\text { ность } \\
\text { L }\end{array}$ & $\begin{array}{c}\text { Эффективность } \\
\text { (число теорети- } \\
\text { ческих тарелок) } \\
\mathrm{N} \\
\end{array}$ & $\begin{array}{c}\text { Размывание } \\
\text { (высота, эквивалент- } \\
\text { ная теоретической } \\
\text { тарелке, Н, мкм }\end{array}$ \\
\hline \multicolumn{6}{|c|}{$\begin{array}{c}\text { Элюирующая система №1. Хлороформ-метанол-вода 100:25:3 } \\
\text { Полярность системы Р’=4.4 ед.пол. }\end{array}$} \\
\hline 1 & 0.15 & 4.0 & 0.62 & 925 & 138.3 \\
\hline 2 & 0.22 & 1.0 & 0.95 & 4340 & 29.5 \\
\hline 3 & 0.23 & 4.4 & 0.70 & 3600 & 35.6 \\
\hline 4 & 0.30 & 14.6 & 0.26 & 9025 & 14.2 \\
\hline 5 & 0.62 & 2.3 & 0.77 & 6241 & 20.5 \\
\hline 6 & 0.68 & 3.5 & 0.79 & 13456 & 9.5 \\
\hline 7 & 0.73 & 3.5 & 0.76 & 14376 & 8.9 \\
\hline 8 & 0.78 & 1.0 & 0.89 & 17777 & 7.2 \\
\hline 9 & 0.80 & 1.1 & 0.76 & 18860 & 6.8 \\
\hline 10 & 0.84 & & & 4702 & 27.3 \\
\hline \multicolumn{6}{|c|}{$\begin{array}{c}\text { Элюирующая система №2. Хлороформ-метанол-25\% аммиак 25:10:1 } \\
\text { Полярность системы Р'=4.0 ед.пол. }\end{array}$} \\
\hline 1 & 0.16 & $18 . .3$ & 0.14 & 441 & 292.5 \\
\hline 2 & 0.58 & 2.4 & 0.85 & 22500 & 5.7 \\
\hline 3 & 0.62 & 2.0 & 0.80 & 11377 & 11.3 \\
\hline 4 & 0.67 & 1.2 & 0.79 & 13456 & 9.6 \\
\hline 5 & 0.72 & 3.5 & 0.24 & 5535 & 23.3 \\
\hline 6 & 0.84 & 1.5 & 0.63 & 11664 & 11.0 \\
\hline 7 & 0.89 & & & 13225 & 9.8 \\
\hline \multicolumn{6}{|c|}{$\begin{array}{c}\text { Элюирующая система №3. Бутанол-этанол- } 25 \% \text { аммиак 7:2:5 } \\
\text { Полярность системы P'=6.3 ед.пол. }\end{array}$} \\
\hline 1 & 0.36 & & & 12544 & 6.1 \\
\hline 2 & 0.43 & 2.1 & 0.75 & 1936 & 39.8 \\
\hline 3 & 0.52 & 3.0 & 0.69 & 25600 & 3.0 \\
\hline 4 & 0.58 & 2.5 & 0.78 & 3600 & 21.4 \\
\hline 5 & 0.66 & 2.4 & 0.72 & 10404 & 7.4 \\
\hline 6 & 0.81 & 4.0 & 0.44 & 3844 & 20.0 \\
\hline 7 & 0.86 & 2.3 & 0.70 & 7744 & 9.9 \\
\hline \multicolumn{6}{|c|}{$\begin{array}{c}\text { Элюирующая система №4. Бутанол-вода-уксусная кислота 4:1:1 } \\
\text { Полярность системы Р’=5.1 ед.пол. }\end{array}$} \\
\hline 1 & 0.56 & 1.50 & 0.82 & 7744 & 10.2 \\
\hline 2 & 0.61 & 0.86 & 0.84 & 9216 & 8.6 \\
\hline 3 & 0.65 & 0.89 & 0.57 & 1664 & 47.5 \\
\hline 4 & 0.76 & 1.67 & 0.48 & 3600 & 21.9 \\
\hline 5 & 0.87 & & & 19044 & 4.1 \\
\hline
\end{tabular}


Сравнение значений селективности и эффективности процесса разделения сапонинов позволяет сделать вывод о том, что значения эти варьируют в достаточно широком диапазоне для каждой из исследуемых систем, но диапазон варьирования для всех элюентов сходен.

Разрешение двух зон считается полным при $\mathrm{R} \geq 1.5$. Число зон индивидуальных сапонинов, удовлетворяющих этому условию, оказалось одинаковым во всех используемых элюентах. Отсутствие резких отличий между исследуемыми системами объясняется, по-видимому, небольшими отличиями в их полярности.

Решающим фактором при выборе элюирующей системы, наиболее подходящей для дальнейших исследований, стала ее разделительная способность, позволяющая получить максимальное количество зон индивидуальных сапонинов на хроматограмме. Данному условию отвечала только система №1 хлороформ-метанолвода 100:25:3 (полярность 4.5), позволяющая обнаружить на хроматограмме 10 зон индивидуальных сапонинов.

Результаты выбора типа пластины, элюента, проявителя, способа хроматографирования, объема наносимой пробы представлены в таблице 2. Рекомендуемые для дальнейшего использования условия процесса хроматографирования сапонинов листьев плюща представлены в последней колонке таблицы.

Таблица 2. Выбор оптимальных параметров процессов хроматографического разделения и идентификации БАВ листьев плюща в тонком слое сорбента

\begin{tabular}{|c|c|c|c|c|c|}
\hline Изучаемые & \multicolumn{4}{|c|}{ Исследуемые параметры } & \multirow{2}{*}{\begin{tabular}{|c|} 
Опти- \\
мальные пара- \\
метры ТСХ \\
сапонинов \\
плюща \\
\\
Sorbfill ПТСХ- \\
П-В 100x100 мм
\end{tabular}} \\
\hline $\begin{array}{c}\text { Тип и размер } \\
\text { пластины }\end{array}$ & $\begin{array}{l}\text { Sorbfill ПТСХ- } \\
\text { АФ-А-УФ } \\
\text { 100x100 мм }\end{array}$ & $\begin{array}{c}\text { Sorbfill } \\
\text { ПТСX-АФ- } \\
\text { А 100x100 мм }\end{array}$ & $\begin{array}{c}\text { Sorbfill } \\
\text { ПТХ-П-А- } \\
\text { УФ } \\
\text { 100х100 мм }\end{array}$ & $\begin{array}{c}\text { Sorbfill } \\
\text { ПТСХ-П- } \\
\text { В 100x100 } \\
\text { мм } \\
\end{array}$ & \\
\hline $\begin{array}{c}\text { Объем } \\
\text { пробы, мкл }\end{array}$ & 5 & 10 & 20 & 30 & 10 \\
\hline $\begin{array}{r}\text { Состав } \\
\text { элюента }\end{array}$ & $\begin{array}{c}\text { Хлороформ- } \\
\text { метанол-вода } \\
\text { 100:25:3 }\end{array}$ & $\begin{array}{c}\text { Хлороформ- } \\
\text { метанол-25\% } \\
\text { аммиак } \\
100: 40: 4\end{array}$ & $\begin{array}{c}\text { Бутанол- } \\
\text { этанол-25\% } \\
\text { аммиак } \\
7: 2: 5\end{array}$ & $\begin{array}{c}\text { Бутанол- } \\
\text { вода- } \\
\text { уксусная } \\
\text { кислота } \\
4: 1: 1\end{array}$ & $\begin{array}{c}\text { Хлороформ- } \\
\text { метанол-вода } \\
\text { 100:25:3 }\end{array}$ \\
\hline $\begin{array}{c}\text { Способ хро- } \\
\text { матографиро- } \\
\text { вания }\end{array}$ & $\begin{array}{c}\text { Восходящее } \\
\text { одноступенча- } \\
\text { тое }\end{array}$ & $\begin{array}{c}\text { Восходящее } \\
\text { двухступен- } \\
\text { чатое }\end{array}$ & $\begin{array}{l}\text { Восходя- } \\
\text { щее } \\
\text { Двумер- } \\
\text { ное } \\
\end{array}$ & - & $\begin{array}{c}\text { Восходящее } \\
\text { одноступенчатое }\end{array}$ \\
\hline $\begin{array}{l}\text { Детектиро- } \\
\text { вание зон } \\
\text { (реактив) }\end{array}$ & $\begin{array}{c}0.2 \% \\
\text { спиртовой рас- } \\
\text { твор пара- } \\
\text { оксибензальде- } \\
\text { гида в } 1 \text { М сер- } \\
\text { ной кислоте }\end{array}$ & $\begin{array}{c}20 \% \text { спир- } \\
\text { товой раствор } \\
\text { фосфорно- } \\
\text { вольфрамо- } \\
\text { вой кислоты }\end{array}$ & $\begin{array}{c}10 \% \\
\text { спиртовой } \\
\text { раствор } \\
\text { серной } \\
\text { кислоты }\end{array}$ & $\begin{array}{c}10 \% \\
\text { спиртовой } \\
\text { раствор } \\
\text { фосфорно- } \\
\text { молибде- } \\
\text { новой } \\
\text { кислоты }\end{array}$ & $\begin{array}{c}0.2 \% \text { спирто- } \\
\text { вой раствор } \\
\text { пара- } \\
\text { окси- } \\
\text { бензальдегида } \\
\text { в } 1 \text { М } \\
\text { серной } \\
\text { кислоте }\end{array}$ \\
\hline
\end{tabular}

Лучше всего себя зарекомендовали высокоэффективные пластины Sorbfill ПТСХ-П-В, хотя неплохое разделение позволяют получить и обычные пластины 
Sorbfill ПТСХ-АФ-А. Оптимальный объем пробы - 10 мкл. Попытки улучшить разделение применением двукратного и двухмерного элюирования к успеху не привели из-за сильного размывания зон.

Наилучшим проявителем можно считать $0.2 \%$ спиртовой раствор параоксибензальдегида в $1 \mathrm{M}$ серной кислоте, который не только окрашивает зоны сапонинов, но и позволяет дифференцировать по цвету зон производные различных агликонов: стероидные - малиновые, производные олеаноловой кислоты - розовые, производные хедерагенина - сиреневые и фиолетовые. Данный детектирующий реагент обеспечивает так же максимальную чувствительность определения.

В отработанных условиях получены хроматографические профили извлечений из листьев Плюща и исследована возможность их использования в качестве «отпечатков пальцев» для идентификации растительного сырья плюща. Хроматографические профили извлечений из исследуемых образцов листьев плюща (среднее из трех параллельных измерений, погрешность определения $\mathrm{R}_{\mathrm{f}}$ составляет $\left.\pm 0.01-0.02\right)$ представлены в таблице 3.

Анализируя данные таблицы, можно сделать вывод о том, что полученные хроматограммы достаточно информативны и могут выполнять роль «отпечатков пальцев» при проведении идентификации ЛРС плюща, поскольку содержат от 9 (Италия, Крым) до 12 (Ирак) зон БАВ, дающих характерную для сапонинов окраску после проявления. Среди этих зон идентифицированы от 4 до 7 зон сапонинов, присутствующих в фитокомплексе Хедерикс+ (сравнение величин Rf с образцом, нанесенным на ту же пластину). На хроматограммах при просмотре в видимом и УФсвете обнаруживается так же более 10 зон сопутствующих соединений. Двойное детектирование зон на одной пластине позволяет сократить время анализа и значительно снизить вероятность ошибочной трактовки результатов.

Таблица 3. Характеристика хроматографических профилей БАВ в метанольных извлечениях из листьев плюща

\begin{tabular}{|c|c|c|c|c|c|c|c|c|}
\hline \multirow{2}{*}{$\begin{array}{c}\text { № } \\
\text { зоны }\end{array}$} & \multicolumn{5}{|c|}{$\begin{array}{c}\mathrm{R}_{\mathrm{f}} \text { зон БАВ на хроматограммах извле- } \\
\text { чений из листьев плюща }\end{array}$} & \multirow{2}{*}{$\begin{array}{c}\text { Окраска зо- } \\
\text { ны в види- } \\
\text { мом свете }\end{array}$} & \multirow{2}{*}{$\begin{array}{c}\text { Окраска } \\
\text { зоны в } \\
\text { УФ-свете } \\
\lambda=365 \text { нм }\end{array}$} & \multirow{2}{*}{$\begin{array}{c}\text { Идентифи- } \\
\text { кация } \\
\text { зон }\end{array}$} \\
\hline & Италия & Ирак & Крым & Кавказ & $\begin{array}{l}\text { Хеде } \\
\text { рикс }\end{array}$ & & & \\
\hline 1 & 2 & 3 & 4 & 5 & 6 & 7 & 8 & 9 \\
\hline 1 & 0.92 & 0.94 & 0.93 & 0.93 & - & Черная & $\begin{array}{c}\text { Коричне } \\
\text { вая }\end{array}$ & $\begin{array}{l}\text { Не иденти- } \\
\text { фицировано }\end{array}$ \\
\hline 2 & 0.90 & 0.92 & 0.91 & 0.91 & - & $\begin{array}{c}\text { Темно- } \\
\text { зеленая }\end{array}$ & Красная & $\begin{array}{c}\text { Хлоро } \\
\text { филл }\end{array}$ \\
\hline 3 & - & 0.83 & 0.83 & 0.83 & 0.84 & Фиолетовая & - & Сапонин \\
\hline 4 & & & & & 0.80 & Розовая & - & Сапонин \\
\hline 5 & - & 0.77 & - & 0.77 & 0.78 & Фиолетовая & - & Сапонин \\
\hline 6 & & & & & 0.73 & Розовая & - & Сапонин \\
\hline 7 & 0.70 & 0.70 & - & 0.69 & - & Фиолетовая & $\begin{array}{c}\text { Розовая. } \\
\text { Ирак - } \\
\text { голубая }\end{array}$ & $\begin{array}{l}\text { Не иденти- } \\
\text { фицировано }\end{array}$ \\
\hline 8 & - & - & - & - & 0.68 & Фиолетовая & - & Сапонин \\
\hline 9 & 0.65 & 0.65 & 0.65 & 0.65 & & Фиолетовая & Розовая & Не идентиф. \\
\hline 10 & - & - & - & - & 0.62 & Малиновая & - & Сапонин \\
\hline 11 & 0.59 & 0.59 & - & 0.59 & - & Фиолетовая & Розовая & Не идентиф. \\
\hline 12 & - & 0.56 & 0.56 & - & - & Фиолетовая & - & Сапонин \\
\hline 13 & 0.54 & 0.54 & - & 0.54 & - & - & Розовая & Не идентиф. \\
\hline 14 & 0.51 & - & - & 0.51 & - & Фиолетовая & - & Сапонин \\
\hline 15 & 0.49 & 0.49 & 0.49 & 0.49 & - & - & Красная & Не идентиф. \\
\hline
\end{tabular}




\begin{tabular}{|c|c|c|c|c|c|c|c|c|}
\hline 1 & 2 & 3 & 4 & 5 & 6 & 7 & 8 & 9 \\
\hline 16 & 0.45 & 0.46 & 0.46 & 0.44 & - & Фиолетовая & - & Сапонин \\
\hline 17 & 0.39 & 0.39 & 0.39 & 0.39 & - & $\begin{array}{c}\text { розовая } \\
\text { Крым- } \\
\text { малиновая }\end{array}$ & $\begin{array}{c}\text { Сиреневая } \\
\text { Крым -нет } \\
\text { окраски }\end{array}$ & $\begin{array}{c}\text { Не иденти- } \\
\text { фицировано }\end{array}$ \\
\hline 18 & 0.33 & 0.33 & - & 0.33 & - & - & Сиреневая & Сапонин \\
\hline 19 & - & - & - & - & 0.30 & Розовая & - & Сапонин \\
\hline 20 & 0.23 & - & - & - & 0.23 & Сиреневая & - & Сапонин \\
\hline 21 & - & 0.20 & 0.19 & 0.19 & 0.22 & Сиреневая & - & Сапонин \\
\hline 22 & - & 0.17 & - & - & - & Сиреневая & - & Сапонин \\
\hline 23 & 0.14 & - & - & - & 0.15 & Сиреневая & - & Сапонин \\
\hline 24 & - & 0.10 & 0.11 & 0.11 & - & Сиреневая & - & Сапонин \\
\hline & & & & & & & $\begin{array}{c}\text { Италия, } \\
\text { Ирак - } \\
\text { голубая. } \\
\text { Крым, Кав- } \\
\text { каз -синяя }\end{array}$ & $\begin{array}{c}\text { Не иденти- } \\
\text { фицировано }\end{array}$ \\
\hline
\end{tabular}

Полученные различия в «отпечатках пальцев» извлечений из растений, произраставших в разных географических зонах, свидетельствуют о вариабельности хроматографических профилей метанольных извлечений из листьев плюща в зависимости от места произрастания растения.

\section{Заключение}

Установлены оптимальные условия анализа сапонинсодержащих извлечений из листьев плюща обыкновенного методом ТСХ. В подобранных условиях получены хроматографические профили извлечений, показана возможность их использования в качестве «отпечатков пальцев» для идентификации растительного сырья плюща. Установлена вариабельность хроматографических профилей извлечений из листьев плюща и ее зависимость от места произрастания растения. Полученные данные могут быть рекомендованы для использования при разработке нормативной документации на лекарственное растительное сырье плюща.

\section{Список литературы}

1. Лавренов В.К. Современная энциклопедия лекарственных растений. М. ОЛМА Медиагрупп. 2007. 272 с.

2. Государственный реестр лекарственных средств. Режим доступа: https://grls.rosmin zdrav.ru/Default.aspx (Дата обращения: 10.09.2018)

3. Государственная фармакопея РФ XIV издания. 2018. Т. 2. С.880.

4. Яковишин Л.А., Гришковец В.И., Корж Е.Н. // Ученые записки Крылского федерального университета имени В. И. Вернадского «Биология, химия». 2015. Т. 1 (67). № 4. С. 163-169.
5. Yakovishin L.A.,Grishkovets V.L. // Studies in Natural Products Chemistry. 2018. Vol. 55, pp. 351-383.

6. Яковишин Л.А. Дисс. док. хим. наук. Казань. 2018. 35 с.

7. Деканосидзе Г. Е., Чирва В.А., Сергеенко Т.В., Уварова Н.И. Исследование тритерпеновых гликозидов (установление строения и синтез). Тбилиси, Мецниереба. 1982. 151 с.

8. Яковишин Л.А., Гришковец В.И., Жолудь И.А. // Методы и объекты химического анализа. 2011. № 2. С 88-92.

9. Яковишин Л.О., Кузнецова Г.Л., Рубинсон М.А., Корж О.М. // Фармац. журн. 2006. №6. C. 62-65. 
10. Яковишин Л.А., Вожжова М.А., Кузнецова А.Л., Гришковец В.И. // Журнал органической и фармачевтической химии. 2005. № 3. С. 57-59.

11. Яковішин Л.О. Гришковець В.И., Корж О.М. // Фармач. журнн. 2010. №3. С. 56-60.

12. Яковишин Л.А. // Химия природных соединений. 2003. № 5. С. 419-420.

13.Яковишин Л.А. // Химия растительного сырья. 2015. № 1. С. 83-87.

\section{References}

1. Lavrenov V.K. Sovremennaja jenciklopedija lekarstvennyh rastenij, M., OLMA Mediagrupp, 2007, $272 \mathrm{p}$.

2. Gosudarstvennyj reestr lekarstvennyh sredstv. Rezhim dostupa: https://grls.rosminzdrav.ru/Default.aspx (Data obrashhenija: 10.09.2018)

3. State Pharmacopoeia of the Russian Federation XIV edition, 2018, V. 2, P.880.

4. Jakovishin L.A., Grishkovec V.I., Korzh E.N., Uchenye zapiski Krymskogo federal'nogo universiteta imeni V. I. Vernadskogo «Biologija, khimija», 2015, Vol. 1 (67), No 4, pp. 163-169.

5. Dekanosidze G.E., Chirva V.A., Sergeenko T.V., Uvarova N.I., Issledovanie triterpenovyh glikozidov (ustanovlenie stroenija $i$ sintez). Tbilisi, Mecniereba, 1982, $151 \mathrm{p}$.

6. Jakovishin L.A., Grishkovec V.I., Zholud' I.A., Metody i ob'ekty himicheskogo analiza, 2011, No 2, pp. 88-92.

7. Jakovishin L.O., Kuznecova G.L., Rubinson M.A., Korzh O.M., Farmac. zhurn., 2006, No 6, pp. 62-65.

Брежнева Татьяна Александровна - к.фарм.н., доцент кафедры фармацевтической химии и фармацевтической технологии, Воронежский государственный университет, Воронеж, $+7(473) 2530428$

Солодухина Анна Анатольевна - аспирантка кафедры фармацевтической химии и фармацевтической технологии фармацевтического факультета ВГУ, Воронеж

Попова Маргарита Васильевна - студентка 4 го курса фармацевтического факультета ВГУ, Воронеж

Самсонова Надежда Данииловна - студентка 5-го курса фармацевтического факультета ВГУ, Воронеж

Сливкин Алексей Иванович - д.ф.н., професcop, зав. кафедрой фармацевтической химии и фармацевтической технологии, декан фармацевтического факультета ВГУ, Воронеж
14. EUROPEAN PHARMACOPOEIA - 8th EDITION published 15 July 2013. Режим доступа: http://www.fptl.ru/biblioteka/farmakopei/ evropeyskaya_farmakopeya_8_vol-1.pdf (Дата обращения: 20.08.2018)

15.Гейсс Ф. Основы тонкослойной хроматографии. М. Мир. 1999. 405 с.

16.Шаршунова М., Шварц В., Михалец Ч. Тонкослойная хроматография в фармации и клинической биохимии. М. Мир. 1980. Т. 2. C. 610 .

8. Jakovishin L.A., Vozhzhova M.A., Kuznecova A.L., Grishkovec V.I., Zhurnal organicheskoj i farmacevticheskoj khimii, 2005, No 3, pp. 57-59.

9. Jakovishin L.O. Grishkovec' V.I., Korzh O.M., Farmac. zhurn., 2010, No 3, pp. 56-60.

10.Jakovishin L.A., Khimija prirodnyh soedinenij, 2003, No 5, pp. 419-420.

11. EUROPEAN PHARMACOPOEIA - 8th EDITION published 15 July 2013. Rezhim dostupa:

http://www.fptl.ru/biblioteka/farmakopei/evrope yskaya_farmakopeya_8_vol-1.pdf (Data obrashhenija: 20.08.2018)

12. Geiss F. Osnovy tonkosloinoi khromatografii, Mir, 1999, $405 \mathrm{p}$.

13. Sharshunova M., V. Schwartz, C. Mihalets. Thin-layer chromatography in pharmacy and clinical biochemistry, Mir, 1980, Vol. 2, pp. 610.

Brezhneva Tatyana A. - the candidate pharm. Sciences, the associate professor, department of pharmaceutical chemistry and pharmaceutical technology, Voronezh State University, Voronezh, e-mail: t brezhneva@mail.ru

Soloduhina Anna A. - post-graduate student, Department of pharmaceutical chemistry and pharmaceutical technology of pharmaceutical faculty, Voronezh State University, Voronezh, mail: ania.soloduhina@yandex.ru

Popova Margarita V. - student of the 4th course of pharmaceutical faculty, Voronezh State University, email: p_margarita@ro.ru

Samsonova Nadezhda D. - student of the 5th course of pharmaceutical faculty, Voronezh State University, Voronezh, e-mail: batisheva-nd@ rambler.ru

Slivkin Alexey I. - PhD. professor, department chair of pharmaceutical chemistry and pharmaceutical technology, dean of pharmaceutical faculty of VSU, Voronezh, e-mail: slivkin@pharm.vsu.ru 